\title{
Overtaking Safety Evaluation and Setting of Auxiliary Lane on Two-Lane Highway in China
}

\author{
Guozhu Cheng, ${ }^{1}$ Lixin Wu, ${ }^{2}$ Liang Xu, ${ }^{3}$ Lihui Qin, ${ }^{4}$ and Yuxia Wang ${ }^{1}$ \\ ${ }^{1}$ School of Transportation Science and Engineering, Harbin Institute of Technology, Harbin 150090, China \\ ${ }^{2}$ School of Transportation Science and Engineering, Jilin Jianzhu University, Changchun 130018, China \\ ${ }^{3}$ School of Civil Engineering, Changchun Institute of Technology, Changchun 130012, China \\ ${ }^{4}$ School of Water Conservancy and Civil Engineering, Northeast Agricultural University, Harbin 150030, China
}

Correspondence should be addressed to Lihui Qin; qinlh1977@163.com

Received 12 October 2015; Accepted 27 October 2015

Academic Editor: Yongjun Shen

Copyright (C) 2016 Guozhu Cheng et al. This is an open access article distributed under the Creative Commons Attribution License, which permits unrestricted use, distribution, and reproduction in any medium, provided the original work is properly cited.

\begin{abstract}
Overtaking experiments on four two-lane highways were conducted. The data of overtaking conflict time (the time difference between the time of driving back to the original lane and the time of meeting with the first opposing vehicle) and experimental drivers' risk feeling were observed. Membership was adopted to denote the experimental drivers' risk feelings which also denote the severity of traffic conflict. Membership ranges from 0 to 1 and corresponding risk becomes higher; that is, traffic conflict becomes more serious. According to the observed relationship between overtaking conflict time, and drivers' risk feeling membership, Cauchy distribution function was adopted as membership function. The thresholds of the severity of traffic conflict were determined through Delphi method. The relationship model among traffic volume, overtaking conflict time and design speed was established according to experimental data. Then the idea of setting auxiliary lane on two-lane highway in China was presented. And the traffic volume values that need setting auxiliary lane corresponding to different design speed and traffic conflict degree were given according to the established model. It is expected to improve the traffic safety level of two-lane highway in China through setting auxiliary lane.
\end{abstract}

\section{Introduction}

By the end of 2013, the total mileage of Chinese classified highway has reached 3.7556 million $\mathrm{km}$ and the ratios of the second-class highway, the third-class highway, and the fourth-class highway are 82 percent. In China, the secondclass highway and the third-class highway are all two-lane highways, and the fourth-class highway can be two-lane or single-lane highway. There is crash risk for overtaking on twolane highway because drivers need overtake on the opposing lane. The overtaking behavior becomes one of the main causes of traffic conflict on two-lane highway. Research on overtaking safety evaluation can provide important evidence for traffic accident prevention of two-lane highway. And setting auxiliary lane can improve the safety level of two-lane highway.

Vlahogianni analyzed factors which may influence the duration of overtaking on two-lane highways [1]. Farah et al. developed models that explain the minimum time to collision and passing gap acceptance by simulator and analyzed age and gender differences in overtaking maneuvers on two-lane rural highways [2-4]. Schneider et al. used the negative binomial model to evaluate the effects of geometric characteristics on rural two-lane highway safety [5]. Montella et al. evaluated drivers' behavior on horizontal curves of two-lane rural highways by simulator [6]. Wu et al. developed mixed logit models to analyze driver injury severities in single-vehicle and multivehicle crashes on rural two-lane highways in New Mexico [7]. Vlahogianni and Golias employed Bayesian networks to model the uncertainty hindering in the overtaking behavior of young drivers on two-lane highways and reveal the related traffic microscopic characteristics that may influence the decision to overtake [8]. Bauer and Harwood studied the safety effects of horizontal curve and grade combinations on rural two-lane highways [9]. Takemoto et al. analyzed the effects of road surface and visibility conditions 


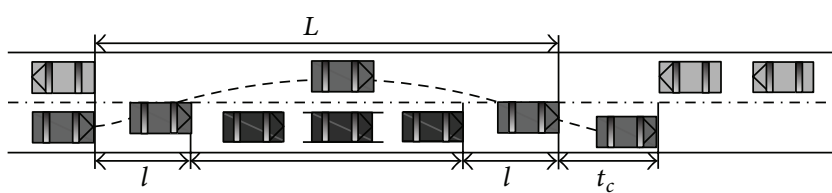

FIGURE 1: Overtaking process on two-lane highway.

on passing-maneuver on two-lane highway [10]. Cafiso et al. presented safety indexes for evaluation of two-lane rural highways [11]. Khan et al. studied the effectiveness of shoulder rumble strips for reducing run-off-the-road crashes on twolane rural highways [12]. Avelar and Carlson studied the relationship between pavement marking retroreflectivity and night safety on Michigan two-lane highways [13]. Zeng and Schrock analyzed safety effectiveness of composite shoulders on rural two-lane highways [14]. Park et al. analyzed the positive safety effects of wider edge lines installed on rural two-lane highways [15]. Correia and Silva studied the speed limit setting on two-lane highway [16]. Wang et al. developed a safety-based approaching behavioural model with driving characteristics [17]. Jiang et al. analyzed the time to collision in traffic conflict [18]. Liu and Bie compared hookturn scheme with U-turn scheme on highway [19]. Bie et al. calibrated platoon dispersion parameter considering the impact of the number of lanes [20].

In summary, recent related researches have mostly focused on risk evaluation by simulator, traffic accidents, affecting factors of safety, and safety countermeasures on twolane highways. A study on setting auxiliary lane on two-lane highway based on conflicts analysis by field experiment was conducted in this paper. In Section 2, an experiment was designed to get conflict data and drivers' risk perception. Subsequently, Section 3 studied the overtaking safety evaluation method and traffic volume condition of setting auxiliary lane on two-lane highway. Finally, a conclusion was made in Section 4.

\section{Experiment}

2.1. Overtaking Process Analysis. The overtaking process on two-lane highway is shown in Figure 1. In Figure $1, l$ is the safe distance, and $L$ is overtaking distance.

Firstly, overtaking vehicle drives into the lane of opposing direction to overtake forward vehicles, and there is a traffic conflict between overtaking vehicle and opposing vehicle. Then overtaking vehicle drives back into the original lane, and there is a traffic conflict between overtaking vehicle and overtaken vehicle. However, overtaking driver will choose a safe chance to drive back into original lane, so the object of the research is the traffic conflict between overtaking vehicle and opposing vehicle. At present, there are mainly two kinds of methods to measure the severity of traffic conflict, that is, time and space distance methods. Considering the convenience of data collection, the time distance was selected as the index to measure the severity of traffic conflict. In Figure $1, t_{c}$ is defined as overtaking conflict time. It is the time difference between the time of driving back to the original lane and the time of meeting with the first opposing vehicle.
2.2. Experiment Design. Two second-class highways and two third-class highways in Harbin, China, were selected as experimental highways. The experiments were conducted from March 10 to April 10, 2013.

This experimental scheme was designed to collect the data of overtaking conflict time and record driver's feeling on overtaking risk. Recorder should record the memberships of driver's feeling on overtaking risk. The memberships belong to $(0,1)$, and the more risk the driver feels, the bigger the membership is. Other collected data include speed of overtaking and overtaken vehicle and traffic volume. The data of overtaking conflicts time were obtained by stop watch. The data of speed were obtained by laser speed measurement. And the data of traffic volume were obtained by erecting camera on the experimental section.

It is acceptable when the experimental sample size is greater than or equal to 3 times of the number of independent variables. In this paper, the relation model has three variables, that is, overtaking conflict time, traffic volume, and design speed. Considering the risk of experiment, experimental sample size was determined as 10. It met the statistic demand. The experimental data were listed in Table 1.

\section{Results and Discussion}

3.1. Overtaking Safety Evaluation. In order to describe the severity of traffic conflict accurately, Delphi method and assignment method based on the fuzzy theory were adopted to analyze the traffic conflict qualitatively, and then the membership function of overtaking conflict time was given. Conflicts were classified into serious, general, and minor conflicts.

3.1.1. The Membership Function. In order to get the membership function of overtaking conflict time, the original data must be analyzed statistically. Table 1 showed that the minimum value of $t_{c}$ is $1 \mathrm{~s}$ and the maximum value of $t_{c}$ is $10 \mathrm{~s}$. According to the incremental order of $t_{c}$ in Table 1, overtaking conflict time and membership were arranged as follows: $(1,0.95),(2,0.9),(3,0.8),(3,0.75),(4,0.65),(5$, $0.5),(5,0.55),(7,0.3),(10,0.1)$, and $(10,0.05)$. Then the trend curve of membership function was obtained and it was shown in Figure 2. In Figure 2, the horizontal axis stands for overtaking conflict time (unit: s) and the vertical axis stands for membership. It can be regarded as the original shape of membership function curve of overtaking conflict time.

Through analyzing the relation between overtaking conflict time and membership in Figure 2, it can be found that it is a monotone decreasing function which is consistent with the $Z$ membership function form. Therefore Cauchy distribution function was chosen as membership function of overtaking conflict time. Cauchy distribution function was shown as follows:

$$
A(x)= \begin{cases}1, & x \leq a, \\ \frac{1}{1+\alpha(x-a)^{\beta}}, & x>a(\alpha>0, \beta>0) .\end{cases}
$$


TABLE 1: Experimental data.

\begin{tabular}{|c|c|c|c|c|c|c|c|}
\hline Number & $\begin{array}{l}\text { Traffic volume } \\
\text { (veh/h/ln) }\end{array}$ & $\begin{array}{l}\text { Overtaking speed } \\
(\mathrm{km} / \mathrm{h})\end{array}$ & $\begin{array}{l}\text { Overtaken speed } \\
(\mathrm{km} / \mathrm{h})\end{array}$ & $\begin{array}{c}\text { Design speed } \\
(\mathrm{km} / \mathrm{h})\end{array}$ & $\begin{array}{l}\text { Overtaking time } \\
\text { (s) }\end{array}$ & $\begin{array}{l}\text { Overtaking conflict time } \\
\text { (s) }\end{array}$ & Risk membership \\
\hline 1 & 520 & 63.8 & 53.6 & 80 & 4 & 3 & 0.75 \\
\hline 2 & 361 & 54.8 & 49.9 & 80 & 6 & 4 & 0.65 \\
\hline 3 & 429 & 69.4 & 57.6 & 80 & 3 & 5 & 0.55 \\
\hline 4 & 831 & 52.2 & 40.2 & 60 & 3 & 1 & 0.95 \\
\hline 5 & 465 & 45.9 & 40.3 & 60 & 6 & 2 & 0.90 \\
\hline 6 & 484 & 54.0 & 45.0 & 60 & 4 & 3 & 0.80 \\
\hline 7 & 321 & 27.1 & 23.0 & 40 & 6 & 5 & 0.50 \\
\hline 8 & 210 & 35.8 & 30.2 & 40 & 7 & 10 & 0.05 \\
\hline 9 & 292 & 30.0 & 22.5 & 30 & 5 & 7 & 0.35 \\
\hline 10 & 217 & 36.5 & 30.4 & 30 & 7 & 10 & 0.10 \\
\hline
\end{tabular}

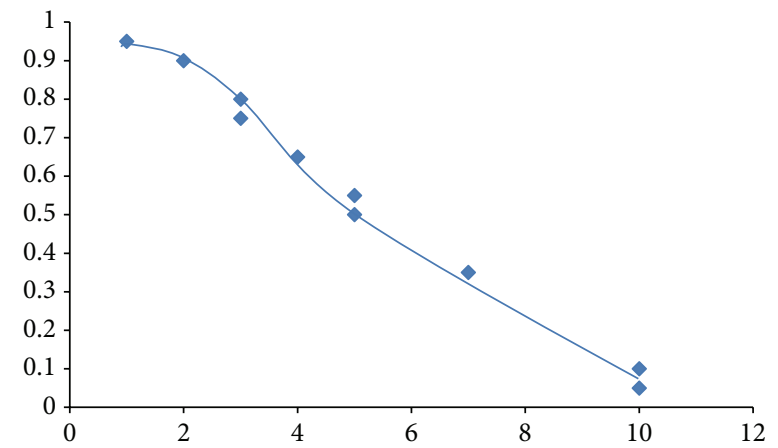

FIGURE 2: Trend curve of membership function.

Figure 2 showed that $a$ equals $2 \mathrm{~s}$. According to data in Figure 2, parameters of formula (1) can be calibrated; that is, $\alpha=1 / 5$ and $\beta=2$. Then the membership function of overtaking conflicts was shown as follows:

$$
A(x)= \begin{cases}1, & x \leq 2 \\ \frac{1}{1+(1 / 5)(x-2)^{2}}, & x>2 .\end{cases}
$$

3.1.2. Membership Thresholds. Considering the fuzzy characteristic of traffic conflict degree, Delphi method was used to determine the membership thresholds of serious conflict, general conflict, and minor conflict. After three times where Delphi method is used, final expert prediction values can be obtained. The third surveying results by Delphi method were shown in Table 2.

(1) Calculation of Arithmetic Mean Value. According to the data in Table 2, arithmetic mean values of the membership threshold can be calculated. Arithmetic mean value of membership threshold between minor and general conflicts is $(0.24+0.36+0.48) / 3=0.36$. Arithmetic mean value of membership threshold between general and serious conflicts is $(0.58+0.75+0.86) / 3=0.73$.

(2) Calculation of Weighted Average Value. Making the minimum, the suitable, and the maximum membership thresholds in Table 2 multiplied by the weights of $0.2,0.6$, and 0.2 , respectively, weighted average values of the membership threshold can be calculated.

Weighted average value of the membership threshold between minor and general conflicts is $0.24 \times 0.2+0.36 \times 0.6+$ $0.48 \times 0.2=0.36$. Weighted average value of the membership threshold between general and the serious conflicts is $0.58 \times$ $0.2+0.75 \times 0.6+0.86 \times 0.2=0.738$.

(3) Calculation of Weighted Median Value. According to the minimum, the suitable, and the maximum values in Table 2, the median values can also be obtained. Then these median values were multiplied by weights of $0.2,0.6$, and 0.2 , respectively.

Weighted median value of the membership threshold between minor and general traffic conflicts is $0.3 \times 0.2+0.35 \times$ $0.6+0.525 \times 0.2=0.375$, and weighted median value of the membership threshold between general and serious conflicts is $0.6 \times 0.2+0.75 \times 0.6+0.9 \times 0.2=0.75$.

In the above three kinds of analysis method, the membership threshold between minor and general conflicts focused on 0.37 , and the membership threshold between general and serious conflicts focused on 0.74 . Thus, the membership of minor conflict belongs to $(0,0.37)$, the membership of general conflict belongs to $[0.37,0.74)$, and the membership of serious conflict belongs to $[0.74,1)$.

3.1.3. Thresholds of Overtaking Conflict Time. By formula (2), thresholds of overtaking conflict time corresponding to each traffic conflict degree were gotten and they were $3.33 \mathrm{~s}, 4.92 \mathrm{~s}$, and $8 \mathrm{~s}$, respectively. The overtaking conflict time corresponding to serious conflict belongs to $(0 \mathrm{~s}, 3.33 \mathrm{~s})$, and the overtaking conflict time corresponding to general conflict belongs to [3.33 s, $4.92 \mathrm{~s}$ ), and the overtaking conflict time corresponding to minor conflict belongs to [4.92 s, $8 \mathrm{~s}$ ].

Therefore, the different conflict degrees by overtaking conflict time $t_{c}$ are measured as follows:

(1) $t_{c} \in(8 \mathrm{~s},+\infty)$. There is no traffic conflict and overtaking can be completed successfully.

(2) $t_{c} \in[4.92 \mathrm{~s}, 8 \mathrm{~s}]$. There is minor conflict and drivers need to observe opposing traffic condition to overtake. 
TABLE 2: Surveying results by Delphi method.

\begin{tabular}{|c|c|c|c|c|c|c|}
\hline \multirow[t]{2}{*}{ Expert's number } & \multicolumn{3}{|c|}{$\begin{array}{l}\text { Membership thresholds between minor } \\
\text { and general conflicts }\end{array}$} & \multicolumn{3}{|c|}{$\begin{array}{l}\text { Membership thresholds between general } \\
\text { and serious conflicts }\end{array}$} \\
\hline & Minimum value & Suitable value & Maximum value & Minimum value & Suitable value & Maximum value \\
\hline 1 & 0.2 & 0.3 & 0.4 & 0.5 & 0.7 & 0.8 \\
\hline 2 & 0.1 & 0.3 & 0.5 & 0.3 & 0.6 & 0.8 \\
\hline 3 & 0.4 & 0.5 & 0.6 & 0.6 & 0.7 & 0.8 \\
\hline 4 & 0.45 & 0.5 & 0.55 & 0.85 & 0.9 & 0.95 \\
\hline 5 & 0.3 & 0.4 & 0.5 & 0.7 & 0.75 & 0.8 \\
\hline 6 & 0.1 & 0.25 & 0.5 & 0.5 & 0.75 & 0.9 \\
\hline 7 & 0.2 & 0.3 & 0.4 & 0.5 & 0.8 & 0.9 \\
\hline 8 & 0.2 & 0.3 & 0.4 & 0.7 & 0.8 & 0.9 \\
\hline Average value & 0.24 & 0.36 & 0.48 & 0.58 & 0.75 & 0.86 \\
\hline
\end{tabular}

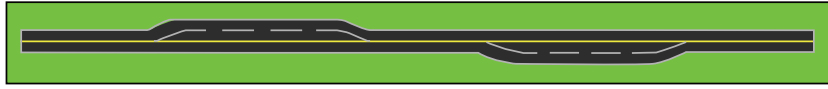

FIGURE 3: Auxiliary lane setting on two-lane highway.

(3) $t_{c} \in[3.33 \mathrm{~s}, 4.92 \mathrm{~s})$. There is general conflict. Drivers need to pay attention to the potential risk and determine whether overtaking or not according to the actual conditions.

(4) $t_{c} \in(0 \mathrm{~s}, 3.33 \mathrm{~s})$. There is serious conflict and drivers need to pay high attention. Traffic accident will happen very likely if drivers overtake, so overtaking determination should be given up. At the same time, managers should study whether the highway capacity of this section is enough.

Results show that the quantitative results are consistent with the actual circumstances. Some of the experimental twolane highways have serious traffic conflict, and they are also the black spots in fact. Thus it can be used for safety evaluation on two-lane highway.

3.2. Setting of Auxiliary Lane on Two-Lane Highway. It can be seen from the above analysis that overtaking is very dangerous if opposing traffic volume is more than certain value. Setting auxiliary lane on the right of original lane can provide space for low-speed vehicle and then high-speed vehicle can overtake using original lane instead of opposing lane so as to guarantee overtaking safety on two-lane highway. Auxiliary lane is shown in Figure 3.

Setting of auxiliary lane on two-lane highway has not been prescribed in Chinese Technical Standard of Highway Engineering (JTG B01-2014) and Design Specification for Highway Alignment (JTG D20-2006). Its setting condition of traffic volume was studied in the following part of this paper.

3.2.1. Relation among Overtaking Conflict Time, Traffic Volume, and Design Speed. It was assumed that the speed of overtaking vehicle after driving back into original lane was the same as the speed of opposing vehicle. It can be seen according to Figure 1 that headway of opposing traffic flow should be the sum of overtaking time $t$, overtaking conflict time $t_{c}$, and driving time of opposing vehicle from meeting location to starting point of overtaking, which equals the sum of $t_{c}$ and the time for driving the distance of $L$. Then the following formula was obtained:

$$
c \frac{3600}{Q}=t+2 t_{c}+a \frac{L}{v_{0} / 3.6},
$$

where $Q$ is traffic volume of opposing lane, veh/h/ln; $t$ is overtaking time, $\mathrm{s} ; v_{0}$ is design speed, $\mathrm{km} / \mathrm{h} ; c$ is the ratio between opposing headway in certain process of overtaking and opposing average headway; $a$ is the ratio between design speed $v_{0}$ and the speed of opposing vehicle.

In formula (3), $L$ can be calculated by the following formula:

$$
L=\frac{v_{2}}{3.6} \cdot t+2 \cdot l=\frac{v_{2}}{3.6} t+2 b v_{0},
$$

where $v_{2}$ is the speed of overtaken vehicle, $\mathrm{km} / \mathrm{h}$, and $b$ is the ratio between the value of safe distance $l$ and the value of design speed $v_{0}$.

Thus, the following formula can be obtained:

$$
c \frac{3600}{Q}=t+2 t_{c}+a\left(\frac{v_{2}}{v_{0}} t+7.2 b\right) .
$$

In formula (5), overtaking time $t$ is related to overtaking speed $v_{1}$ and the speed of overtaken vehicle $v_{2}$. And it is inversely proportional to the difference between $v_{1}$ and $v_{2}$. Therefore, their relation was assumed as follows:

$$
t=d \frac{1}{\left(v_{1}-v_{2}\right)} \quad(d>0)
$$

where $v_{1}$ is overtaking speed, $\mathrm{km} / \mathrm{h}$, and $d$ is the undetermined parameter.

Combining formulas (5) and (6), the following formula can be obtained:

$$
t_{c}=c \frac{1800}{Q}-\frac{1}{2} d \frac{1}{v_{1}-v_{2}}-\frac{1}{2} a d \frac{v_{2}}{v_{0}\left(v_{1}-v_{2}\right)}-3.6 a b .
$$


TABle 3: The processed data.

\begin{tabular}{lcccc}
\hline Number & $t_{c}(\mathrm{~s})$ & $A(\mathrm{~s})$ & $B(\mathrm{~h} / \mathrm{km})$ & $C(\mathrm{~h} / \mathrm{km})$ \\
\hline 1 & 3 & 3.46 & 0.10 & 0.07 \\
2 & 4 & 4.98 & 0.20 & 0.13 \\
3 & 5 & 4.19 & 0.08 & 0.06 \\
4 & 1 & 2.17 & 0.08 & 0.06 \\
5 & 2 & 3.87 & 0.18 & 0.12 \\
6 & 3 & 3.72 & 0.11 & 0.08 \\
7 & 5 & 5.61 & 0.24 & 0.14 \\
8 & 10 & 8.57 & 0.18 & 0.13 \\
9 & 7 & 6.17 & 0.13 & 0.10 \\
10 & 10 & 8.28 & 0.16 & 0.17 \\
\hline
\end{tabular}

TABLE 4: Calibrated model parameters.

\begin{tabular}{lcccc}
\hline $\begin{array}{l}\text { Undetermined } \\
\text { parameters }\end{array}$ & $\begin{array}{c}\text { Calibrated } \\
\text { values }\end{array}$ & $\begin{array}{c}\text { Standard } \\
\text { error }\end{array}$ & $t$ & Sig. \\
\hline$p$ & 1.786 & 0.086 & 20.656 & 0.000 \\
$q$ & -14.196 & 4.392 & -3.232 & 0.003 \\
$m$ & -6.839 & 5.076 & -2.347 & 0.186 \\
$n$ & -1.369 & 0.390 & -3.512 & 0.001 \\
\hline
\end{tabular}

In formula (7), making $1800 / Q=A, 1 /\left(v_{1}-v_{2}\right)=B$, $v_{2} /\left[v_{0}\left(v_{1}-v_{2}\right)\right]=C, c=p, d / 2=q, a d / 2=m, 3.6 a b=n$, then the following formula can be obtained:

$$
t_{c}=p A-q B-m C-n,
$$

where $A$ is half of opposing average headway, $s ; B$ is the reciprocal of the difference between overtaking speed $v_{1}$ and the speed of overtaken vehicle $v_{2}, \mathrm{~h} / \mathrm{km} ; C$ is the product of $B$ and the ratio between the speed of overtaken vehicle $v_{2}$ and design speed $v_{0}, \mathrm{~h} / \mathrm{km} ; p, q, m$, and $n$ are undetermined parameters.

The variables in formula (8) are not data obtained directly by experiment, so data processing is needed. The processed data were listed in Table 3. SPSS software was used to calibrate model parameters; the calibration results were shown in Table 4. It can be seen from Table 4 that $t$ values of three model variables are $20.656,-3.232$, and -2.347 , respectively. Given significance level $\alpha=0.05$, the critical value $t_{\alpha}(36)=$ 2.029. Three absolute values of $t$ were all more than this critical value, so three variables all passed the significant test under 95\% confidence level.

Then the following formula can be obtained:

$$
t_{c}=\frac{3215}{Q}-\frac{14.196}{v_{1}-v_{2}}-\frac{6.839 v_{2}}{v_{0}\left(v_{1}-v_{2}\right)}-1.369
$$

According to observed data, the relation among $v_{1}, v_{2}$, and $v_{0}$ can be obtained; that is, $v_{2}=0.65 v_{0} \sim 0.75 v_{0}$, and $v_{1}=1.2 v_{2}$. According to formula (9), $t_{c}$ is proportional to $v_{1}-v_{2}$. It is safer if the difference between $v_{1}$ and $v_{2}$ is less. Thus $v_{2}=0.65 v_{0}$, and the relation model among overtaking
TABLE 5: Traffic volumes of opposing lane that need setting auxiliary lane (unit: veh/h/ln).

\begin{tabular}{lcccc}
\hline \multirow{2}{*}{ Traffic conflict degree } & \multicolumn{4}{c}{ Design speed $(\mathrm{km} / \mathrm{h})$} \\
& 80 & 60 & 40 & 30 \\
\hline Minor & $288 \sim 398$ & $273 \sim 370$ & $248 \sim 326$ & $227 \sim 290$ \\
General & $398 \sim 495$ & $370 \sim 454$ & $326 \sim 388$ & $290 \sim 339$ \\
Serious & $>495$ & $>454$ & $>388$ & $>339$ \\
\hline
\end{tabular}

conflict time, traffic volume of opposing lane, and design speed can be shown as follows:

$$
t_{c}=\frac{3215}{Q}-\frac{143.395}{v_{0}}-1.369 .
$$

3.2.2. Traffic Volume Condition of Setting Auxiliary Lane. According to formula (10), the following formula can be obtained:

$$
Q=\frac{3215}{t_{c}+143.395 / v_{0}+1.369} .
$$

In formula (11), $t_{c}$ can be determined by traffic conflict degree. Therefore, traffic volume of opposing lane that needs setting auxiliary lane on two-lane highway can be calculated according to traffic conflict and design speed $v_{0}$. The calculated results were listed in Table 5 .

It is suggested that auxiliary lane should be set when traffic volume of opposing lane exceeds the boundary value between minor and general conflicts because serious conflict is very dangerous.

\section{Conclusions}

Based on experiments on two-lane highway, the traffic conflict degree was analyzed qualitatively. The memberships of traffic conflict and the judgmental indexes on two-lane highway in China were obtained. The overtaking conflict time ranges of serious conflict, general conflict, and minor conflict are $(0 \mathrm{~s}, 3.3 \mathrm{~s}$ ), $(3.3 \mathrm{~s}, 4.92 \mathrm{~s}$ ), and $(4.92 \mathrm{~s}, 8 \mathrm{~s}$ ), respectively.

The relation model was established among overtaking conflict time, traffic volume of opposing lane, and design speed. According to this model, traffic volumes of opposing lane that need setting auxiliary lane on two-lane highway were given.

It is suggested that auxiliary lane should be set on two-lane highway when traffic volumes of opposing lane are more than $398 \mathrm{veh} / \mathrm{h} / \mathrm{ln}, 370 \mathrm{veh} / \mathrm{h} / \mathrm{ln}, 326 \mathrm{veh} / \mathrm{h} / \mathrm{ln}$, and $290 \mathrm{veh} / \mathrm{h} / \mathrm{ln}$, respectively, on the two-lane highway with the design speed of $80 \mathrm{~km} / \mathrm{h}, 60 \mathrm{~km} / \mathrm{h}, 40 \mathrm{~km} / \mathrm{h}$, and $30 \mathrm{~km} / \mathrm{h}$.

Auxiliary lane on two-lane highway can provide safe overtaking chance for car by using original lane instead of opposite lane. Thus safety benefit is produced by avoiding traffic accidents. After setting up auxiliary lane on twolane highway, more overtaking opportunities for fast vehicles are provided, so highway capacity and vehicle speed will increase, and traveling delay will reduce. However, setting auxiliary lane will increase the costs of highway construction and maintenance. Setting space of auxiliary lane influences 
directly its application effect and engineering costs, so it should be studied in the future.

\section{Conflict of Interests}

The authors declare that there is no conflict of interests regarding the publication of this paper.

\section{Acknowledgments}

This research was sponsored by Jilin Province Science and Technology Development Project (20140413011GH) and the Scientific Research Foundation for the Returned Overseas Chinese Scholars, State Education Ministry.

\section{References}

[1] E. I. Vlahogianni, "Modeling duration of overtaking in two lane highways," Transportation Research Part F: Traffic Psychology and Behaviour, vol. 20, pp. 135-146, 2013.

[2] H. Farah, S. Bekhor, and A. Polus, "Risk evaluation by modeling of passing behavior on two-lane rural highways," Accident Analysis and Prevention, vol. 41, no. 4, pp. 887-894, 2009.

[3] H. Farah, S. Bekhor, A. Polus, and T. Toledo, "A passing gap acceptance model for two-lane rural highways," Transportmetrica, vol. 5, no. 3, pp. 159-172, 2009.

[4] H. Farah, "Age and gender differences in overtaking maneuvers on two-lane rural highways," Transportation Research Record, vol. 2248, pp. 30-36, 2011.

[5] W. H. Schneider, P. T. Savolainen, and D. N. Moore, "Effects of horizontal curvature on single-vehicle motorcycle crashes along rural two-lane highways," Transportation Research Record, vol. 2194, pp. 91-98, 2010.

[6] A. Montella, F. Galante, L. L. Imbriani, F. Mauriello, and M. Pernetti, "Simulator evaluation of drivers' behaviour on horizontal curves of two-lane rural highways," Advances in Transportation Studies, no. 34, pp. 91-104, 2014.

[7] Q. Wu, F. Chen, G. Zhang, X. C. Liu, H. Wang, and S. M. Bogus, "Mixed logit model-based driver injury severity investigations in single- and multi-vehicle crashes on rural twolane highways," Accident Analysis \& Prevention, vol. 72, no. 11, pp. 105-115, 2014.

[8] E. I. Vlahogianni and J. C. Golias, "Bayesian modeling of the microscopic traffic characteristics of overtaking in two-lane highways," Transportation Research Part F: Traffic Psychology and Behaviour, vol. 15, no. 3, pp. 348-357, 2012.

[9] K. Bauer and D. Harwood, "Safety effects of horizontal curve and grade combinations on rural two-lane highways," Transportation Research Record, vol. 2398, pp. 37-49, 2013.

[10] A. Takemoto, K. Munehiro, N. Takahashi, S. Kasai, S. Yamamoto, and K. Tsutsumi, "Construction of passingmaneuver model on two-lane highway with consideration of road surface and visibility conditions," Transportation Research Record, vol. 2258, pp. 110-118, 2011.

[11] S. Cafiso, G. La Cava, and A. Montella, "Safety index for evaluation of two-lane rural highways," Transportation Research Record, no. 2019, pp. 136-145, 2007.

[12] M. Khan, A. Abdel-Rahim, and C. J. Williams, "Potential crash reduction benefits of shoulder rumble strips in two-lane rural highways," Accident Analysis and Prevention, vol. 75, no. 2, pp. 35-42, 2015.
[13] R. Avelar and P. Carlson, "Link between pavement marking retroreflectivity and night crashes on Michigan two-lane highways," Transportation Research Record, vol. 2404, pp. 59-67, 2014.

[14] H. Zeng and S. Schrock, "Estimation of safety effectiveness of composite shoulders on rural two-lane highways," Transportation Research Record, vol. 2279, pp. 99-107, 2012.

[15] E. S. Park, P. J. Carlson, R. J. Porter, and C. K. Andersen, "Safety effects of wider edge lines on rural, two-lane highways," Accident Analysis and Prevention, vol. 48, no. 9, pp. 317-325, 2012.

[16] G. H. D. A. Correia and A. B. Silva, "Setting speed limits on rural two-lane highways by modeling the relationship between expert judgment and measurable roadside characteristics," Journal of Transportation Engineering, vol. 137, no. 3, pp. 184-192, 2010.

[17] W. Wang, W. Zhang, H. Guo, H. Bubb, and K. Ikeuchi, "A safety-based approaching behavioural model with various driving characteristics," Transportation Research Part C: Emerging Technologies, vol. 19, no. 6, pp. 1202-1214, 2011.

[18] X. Jiang, W. Wang, and K. Bengler, "Intercultural analyses of time-to-collision in vehicle-pedestrian conflict on an urban midblock crosswalk," IEEE Transactions on Intelligent Transportation Systems, vol. 16, no. 2, pp. 1048-1053, 2015.

[19] Z. Liu and Y. Bie, "Comparison of hook-turn scheme with U-turn scheme based on actuated traffic control algorithm," Transportmetrica A: Transport Science, vol. 11, no. 6, pp. 484501, 2015.

[20] Y. Bie, Z. Liu, D. Ma, and D. Wang, "Calibration of platoon dispersion parameter considering the impact of the number of lanes," Journal of Transportation Engineering, vol. 139, no. 2, pp. 200-207, 2013. 


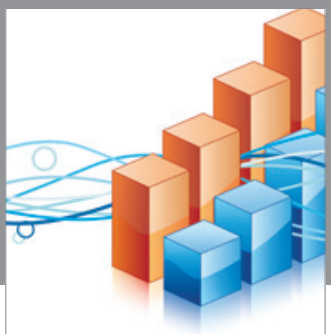

Advances in

Operations Research

vatem alat4

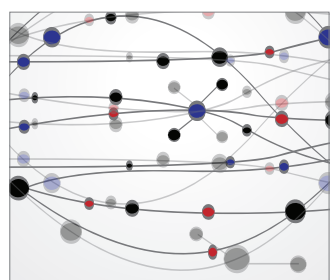

\section{The Scientific} World Journal
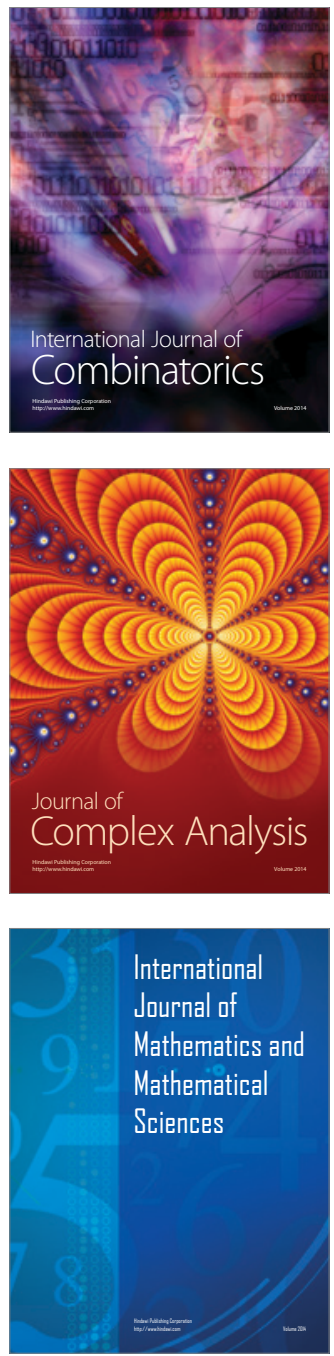
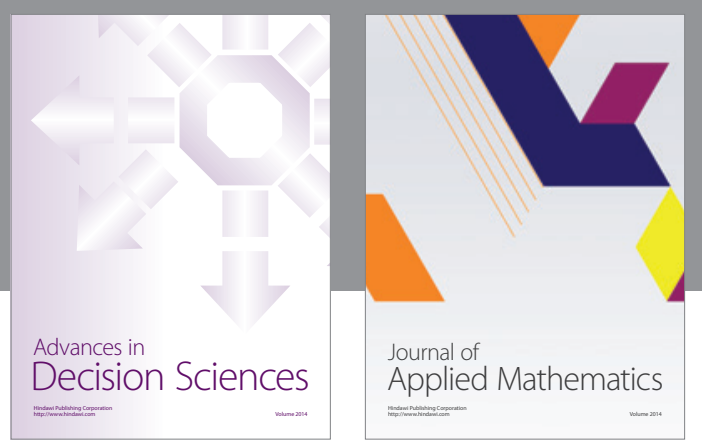

Algebra

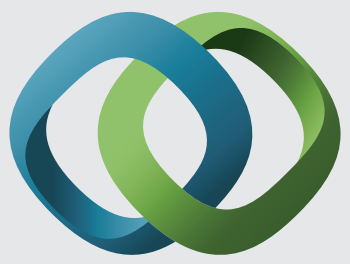

\section{Hindawi}

Submit your manuscripts at

http://www.hindawi.com
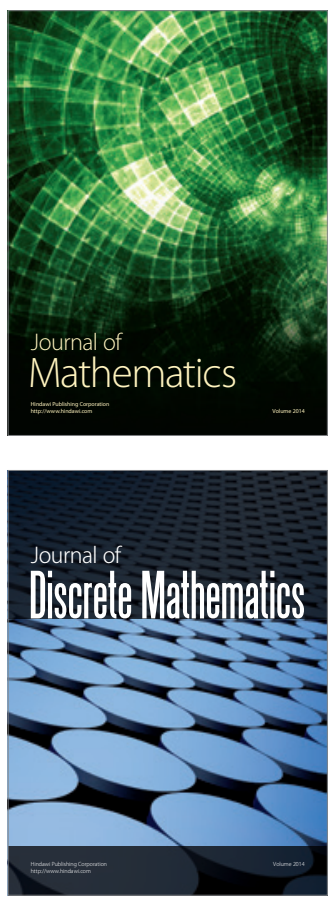

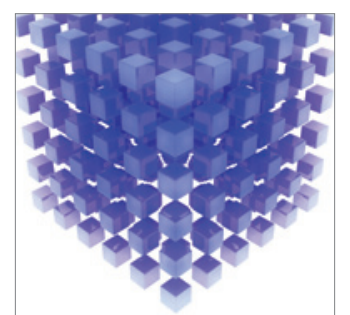

Mathematical Problems in Engineering
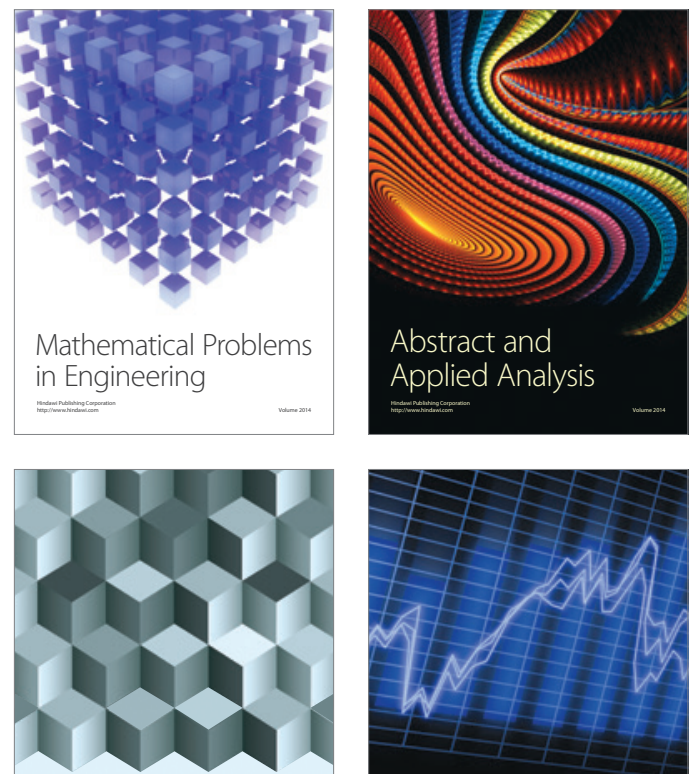

Journal of

Function Spaces

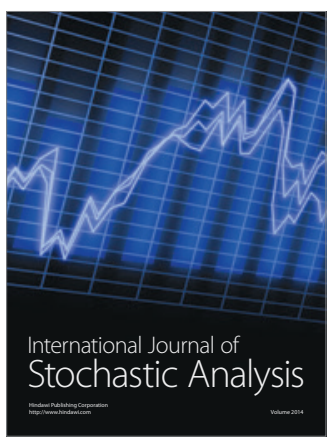

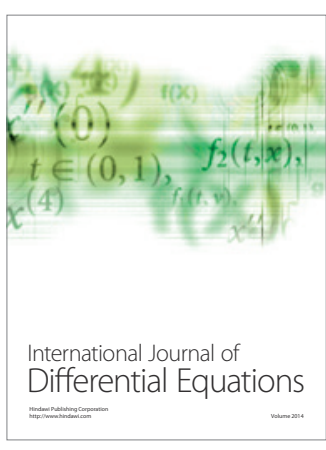
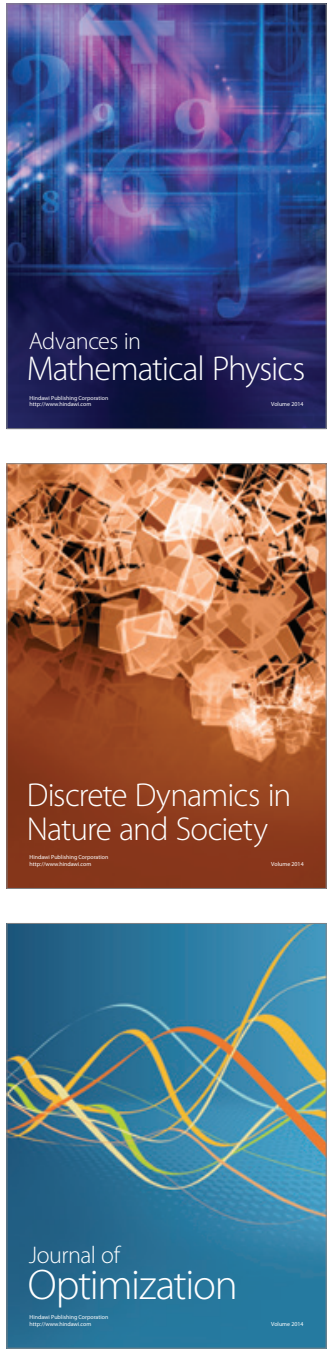